\title{
MODELLING OF THE IMPACT OF A WAVE FARM ON NEARSHORE SEDIMENT TRANSPORT
}

\author{
Raúl González-Santamaría ${ }^{1}$, Qingping Zou² and Shunqi Pan ${ }^{3}$
}

\begin{abstract}
This paper presents the results from an integrated modelling system investigating the effects of a wave farm on nearshore sediment transport. Wave Hub project is a large scale demonstration site for the development of the operation of arrays of wave energy generation devices located at the southwest coast of the UK where multiple field measurements took place. The two-way coupled SWAN and ROMS models with nested modelling system were set up at the Wave Hub site and run with and without a wave farm. The model results show that the presence of the wave farm has significant impacts on the nearshore circulation, bed shear stresses and sediment transport. The morphological changes are also altered by the wave farm. The study is the key element for the wave resource characterization and environmental impact assessment of the wave farm.
\end{abstract}

Keywords: wave-current interaction, renewable energy, ROMS, SWAN, sediment transport, Wave Hub

\section{INTRODUCTION}

Located at the southwest coast of England, the Wave Hub project aimed to create one of the world's largest wave farms for demonstration and testing wave energy converter devices. Recent studies at the Wave Hub site suggest that wave induced currents are important in controlling sediment movement (SWRDA, 2006). Better understanding of tidal effects on waves and sand transport is crucial to wave resource characterization and environmental impact assessment of the wave farm at the Wave Hub site. A numerical study carried out by SWRDA (2006) suggested that the wave energy converters (WECs) installed at the Wave Hub site would cause a reduction between 3\% - 5\% of wave height in the adjacent coast of the Wave Hub, as well as changes in tidal currents and bathymetry. However, in their study the hydrodynamic model, Flow3D, was forced by four tidal constituents during a storm to assess the impact of the deployed WECs on tidal currents and sediment transport. Tidal currents recorded maximum current velocity of $1.2 \mathrm{~m} / \mathrm{s}$, in comparison of the admiralty pilot reported tidal currents between 0.5 and $1.0 \mathrm{~m} / \mathrm{s}$ on the north coast of Cornwall during spring tides. To assess the WECs effect on the studied area, wave dragon devices were used. Model results suggest that sediment transport for this case study changes significantly at the Wave Hub site, but the impact of the wave farm on the adjacent nearshore zone remains an unresolved issue.

Millar et al (2007) carried out a study at the Wave Hub site to estimate the impact of WECs on the nearshore wave climate by analysing the wave energy transmitted through the WECs to the adjacent nearshore region. By comparing the SWAN model results with field observations from wave buoys, they concluded that assuming a $90 \%$ transmission rate, the average reduction in significant wave height was of the order of $1 \mathrm{~cm}$, and that the stretch of the coast most likely to be affected was between Godrevy and Towan Heads that are close to the Wave Hub site.

Buscombe and Scott (2008) have addressed that sand transport due to tides is believed to be weak and not well quantified in this region, and the volume of sand involved is limited in comparison with other sectors of the English coasts. Also it was found that wave induced currents are believed to be more important in controlling sediment movement, not only from the prevailing southerly and westerly winds, but also the easterly winds can produce significant movement of sediment. Although storm events may cause movement of sand on the inner shelf, their effects are greater in the nearshore zone where significant cross- and long-shore sediment transport takes place.

Therefore, there is currently a lack of studies in the nearshore and shoreline areas in the lee side of the wave farm. Following the previous studies of wave-tide interactions at this area (GonzalezSantamaria et al, 2011; Gonzalez-Santamaria et al, 2012), the aim of the present study is to investigate the effect of a wave farm on the wave field, bed shear stresses, sediment transport and morphological changes, particularly along the shoreline behind the wave farm. We use the integrated and fully coupled wave-current numerical modelling system, extended with the sediment transport modules to gain insight into how the wave farm affects the current and bottom friction at the Wave Hub site, as well as sediment transport and the resulting morphological changes.

\footnotetext{
${ }^{1}$ School of Marine Science and Eng, Plymouth University, Plymouth, PL4 8AA, UK

${ }^{2}$ Department of Civil and Environmental Engineering, University of Maine, USA

${ }^{3}$ School of Engineering, Cardiff University, Cardiff, CF24 3AA, UK
} 


\section{METHODOLOGY}

In this study, the spectral wave model SWAN (Booij et al, 1999) and the ocean circulation model ROMS are used to form a fully two-way coupled modelling system (Warner et al, 2008). The schematic diagram of the modelling system is shown in Figure 1. In order to include the far-field effects for waves, the SWAN model is run with three nested domains with progressively finer grid resolutions, as shown in Figure 2. At the finest grid (L3), the SWAN is coupled with the ROMS model to form the coupled modelling system (SWAN+ROMS). The SWAN model is fed by the output of the global wave spectral model Wave Watch III (NOAA: http://polar.ncep.noaa.gov) driven by the wind fields from the Global Forecast System (GFS) model. The global tidal model OTPS (Egbert et al, 2002; Padman and Erofeeva, 2004) provides tidal currents and water elevations as boundary conditions for the ROMS model. The wave model results can be affected by both water elevations and tidal currents, hence, the tidal information obtained from the ROMS model is used in the wave model.

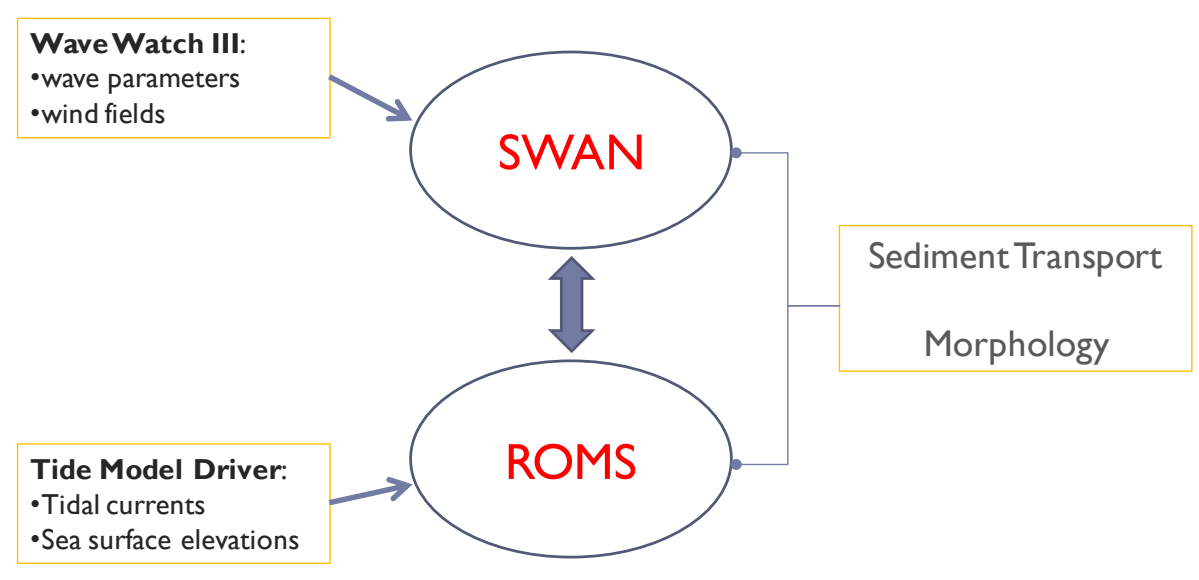

Figure 1. Schematic diagram of the integrated modeling system.

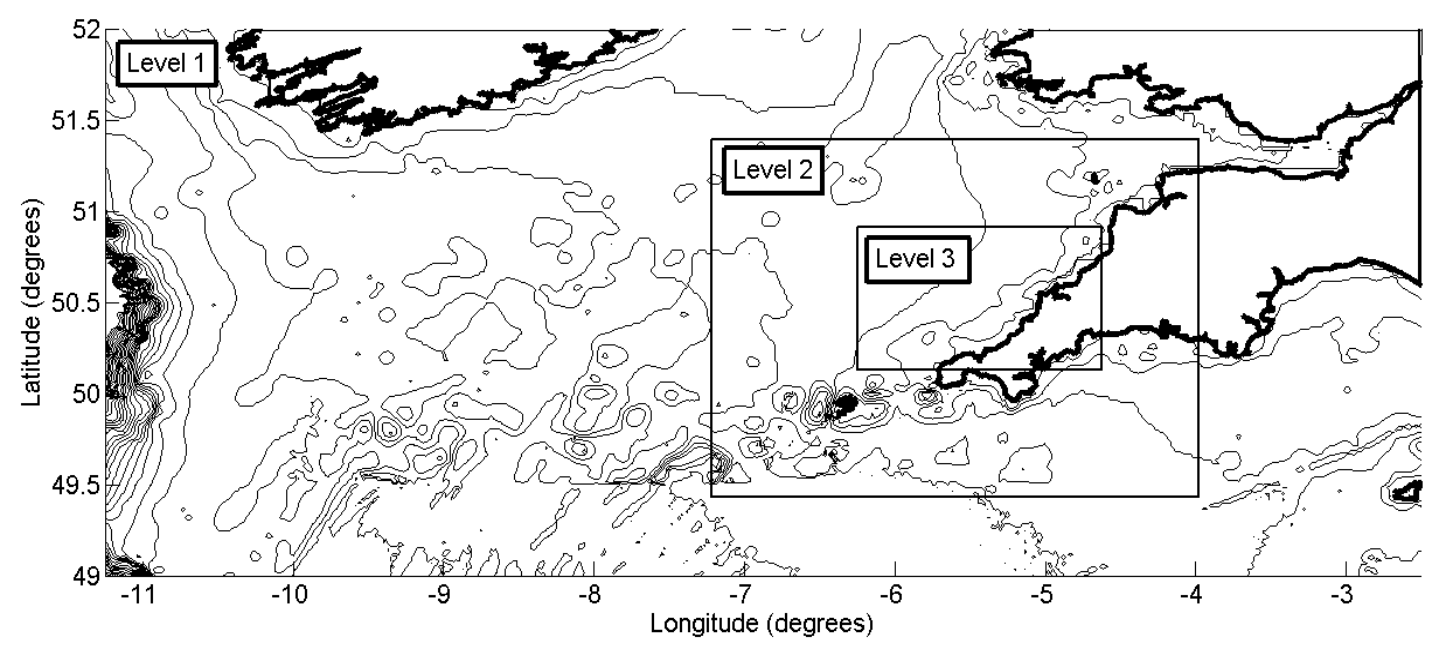

Figure 2. Nested computational domains for SWAN and ROMS.

The Oregon State University Tidal Prediction Software (OTPS/TPXO) based on the TOPEX/POSEIDON altimeter data (Egbert et al, 2002; Padman and Erofeeva, 2004), was used to predict tidal currents and water elevations from eleven harmonic constituents $\left(M_{2}, S_{2}, N_{2}, K_{2}, K_{l}, O_{l}\right.$, $\left.P_{1}, Q_{1}, M_{4}, M S_{4}, M N_{4}\right)$. We found that the predicted water elevations are in a good agreement with the measurements from tide gauges near the Wave Hub site. In addition, a sediment transport model embedded in ROMS was incorporated in the modelling system for computing sediment transport and nearshore morphological changes. The Soulsby and Damgaard (2005) formulae is applied for computing bedload transport which accounts for the combined effects of mean currents and 
asymmetrical waves on bedload flux. Suspended load is transported in the water column by solving the diffusion-advection equation, additional a source/sink term is added in exchange with the bed for vertical settling velocity and erosion. Erosion depends linearly on the bottom shear stress. The bed model accounts for changes in sea floor elevation resulting from convergence or divergence in sediment fluxes. These morphological changes can have an impact on flow transport when they are larger (Warner et al, 2008).

The two-way coupled modelling system consists of two models which are linked with shared information: the ROMS model, which computes sea surface levels, depth averaged horizontal velocity components and bottom stress based on the given sediment grain size; and the SWAN model, which computes wave height, wave length, wave period and wave bottom orbital velocities. Between these two models, the currents and water levels computed in ROMS are used in SWAN and the radiation stresses derived from the SWAN are used to calculate the wave induced current in ROMS, so that the dynamic interaction between waves and tides is realized. In addition, wind fields are used as the surface forcing in the SWAN model for predicting the wave field, but, the wind stress is ignored in the ROMS model due to the relatively small computational domain.

The coupled modelling system (SWAN+ROMS) was first applied to assess the impact of waves on currents and currents on waves. To achieve this, a series of different cases combining spring and neap tides, high and low water levels, high and low wave conditions, were investigated to examine the changes in waves, currents and bottom stresses. Then, the calibrated modelling system was implemented with a wave farm and applied to a storm period to investigate the effects of the wave farm on wave field predictions, bed shear stresses under combined wave and current conditions, sediment transport and the resulting morphological changes, with particular focus on the nearshore area in the lee side of the wave farm.

\section{RESULTS}

\section{Wave-current interaction}

For investigating the wave-current interaction, the modelling system was run for two months, from 1 st December 2005 to 31 st January 2006 in order to match the availability of wave buoy data. Three test cases were selected to examine the space distribution of wave-current interactions through the tidal cycle. These test cases are selected at the peak of the storm and during spring tide: high water level and low current velocities; middle water level and high current velocities; and low water level and low current velocities.

Comparisons between surface current velocities at the Wave Hub site from the coupled modelling system (SWAN+ROMS) and the ROMS (only) model were carried out in Gonzalez-Santamaria et al (2011), where the influence of tidal currents and tidal elevations on the significant wave heights at the Wave Hub site predicted by the coupled system, are compared with the buoy measurements. The model results indicate that the impact of wave-current interactions on the computed current velocities is significant during the spring tides. Similar to the current velocities, the current-induced bottom stresses in a spring tide are significantly affected by the waves. As waves propagate towards the coast, the wave propagation speed and direction may be modified by tidal currents due to refraction. In general, the main changes of wave direction are found during low wave heights and high tidal currents. In the same study three reference locations were compared. It was found that at the Wave Hub site the current magnitudes, after removing the tidal signal, are smaller than those at the nearshore area where the wave action enhances the current significantly. For example, at two nearshore points, the longshore currents vary, at one point from -0.5 to $0.5 \mathrm{~m} / \mathrm{s}$, and at the other point from -0.5 to $1.1 \mathrm{~m} / \mathrm{s}$, as a clear indication of the impact of change of wave direction on the current.

In studying the wave-tide interactions, analysis also includes the wave radiation stress, which is the flux of momentum carried by the ocean waves. When waves disperse in nearshore areas, the wave momentum is transferred to the water column, generating the near-shore currents (Bowen, 1969). Significant momentum can be transferred from waves to currents when a strong radiation stress gradient and radiation stress gradients are determined from the spatial gradients in the directional energy spectrum of the wave model and the strongest gradients in radiation stress occur where depthinduced breaking happens (Mulligan et al, 2008).

Within the fully coupled modelling system, the following physical mechanisms contribute to the wave-current interactions: i) surface shear stress, the effect of surface waves on the drag coefficient is included in ROMS (Warner et al, 2008); ii) bottom stress, waves enhance the turbulent mixing, therefore, waves modify the bottom stress experience by currents (Grant \& Madsen, 1979; Zou, 2004); and iii) radiation stress which represents the excessive momentum flux within the circulation due to the 
presence of waves (Longuet-Higgins and Stewart, 1964; Zou et al, 2006 ). For a hypothetic wave coming from the western boundary, a comparison with and without the wave effect, shown in Figure 3, illustrate the radiation stress influence on the circulation system. This figure shows the transferred momentum from waves to currents in the nearshore region, it worth mention that tidal currents are one order of magnitude higher and, in this case, the surface stress has been idealized over the whole domain. When tidal currents and wave induced currents are combined, the currents at the Wave Hub site are significantly enhanced, compared with the results when the waves are not included. The resultant flow is dominated by the tidal currents which are more uniform away from the coast. However, along the shoreline, currents are enhanced by the wave action through radiation stress gradients. This means that wave induced currents are significant in this zone, even though the tidal currents are the main force for the general circulation.
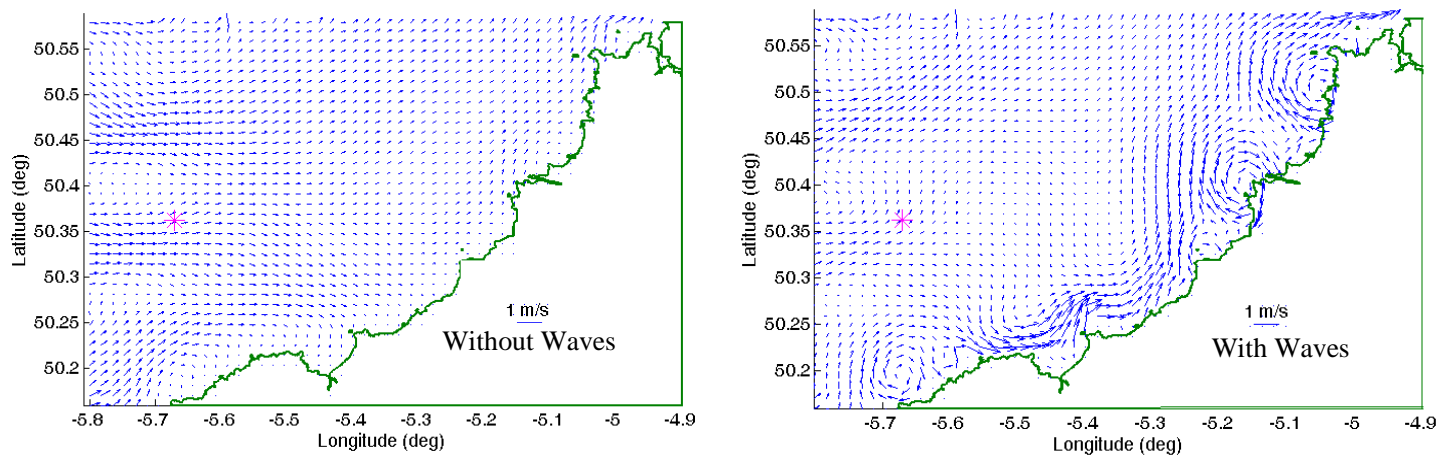

Figure 3. Computed currents with and without waves (* - the Wave Hub).

While during neap tides, the tidal influence on waves is insignificant, during spring tides, the difference becomes more noticeable, this is observed in Gonzalez-Santamaria et al, (2011), where the differences in significant wave height and wave direction and with-without tidal currents are shown, particularly for the cases indicated above within the L3 domain (see Figure 2). Moreover, the difference between the coupled modelling system and the wave model only for the significant wave height and wave direction showed strong correlation of wave height, wave direction and wind velocity, suggesting that wind waves play an important role on the longshore currents, which will affect the sediment transport. It is also found that when tidal currents are included, the wave direction is modified by around 10 degrees during high waves, but about 20 degrees during low waves. The change in wave direction to further align the shore is also an important factor, as this will produce stronger alongshore currents, particularly, during the low water level case.

As shown in Gonzalez-Santamaria et al (2012), the spatial distribution of the wave influence on bottom currents showed larger velocities and eddies along the coast up to $2 \mathrm{~m} / \mathrm{s}$. At high tide and low tidal currents, the region with significant wave induced currents is more confined to the coast. At mid tide, tidal currents are at its maximum, and the total current velocity field is uniform in the offshore zone and increases in magnitude in the nearshore zone where the significant wave height is high. At low tide, tidal currents are at the minimum, the region with significant wave induced currents is extended in the offshore direction due to decreasing water depth. The velocities near the coast are clearly enhanced by the wave forcing, particularly in the longshore direction.

\section{Effects of the wave farm on wave height and bed shear stress}

The wave farm was incorporated in the SWAN model following Millar et al (2007) and arrays of WECs at the Wave Hub site was represented as a $4 \mathrm{~km}$ partially transmitting obstacle, aligning approximately parallel to the prevailing incoming wave crests. The energy transmission percentage was set as $75 \%$ which represents an array of densely spaced, high-efficiency WECs. Figure 4 shows significant wave height (colours) and wave direction (vectors) for the storm case and for the water elevations, even, the difference between with and without the wave farm is shown. The change of the wave height with and without the wave farm is between $5 \mathrm{~cm}$ and $10 \mathrm{~cm}$ at the nearshore line, and the maximum extension affected by the wave farm is about $26 \mathrm{~km}$ northwards St. Ives Bay (south of L3) for the high water level case when the most significant wave farm impact on wave height occurs. 


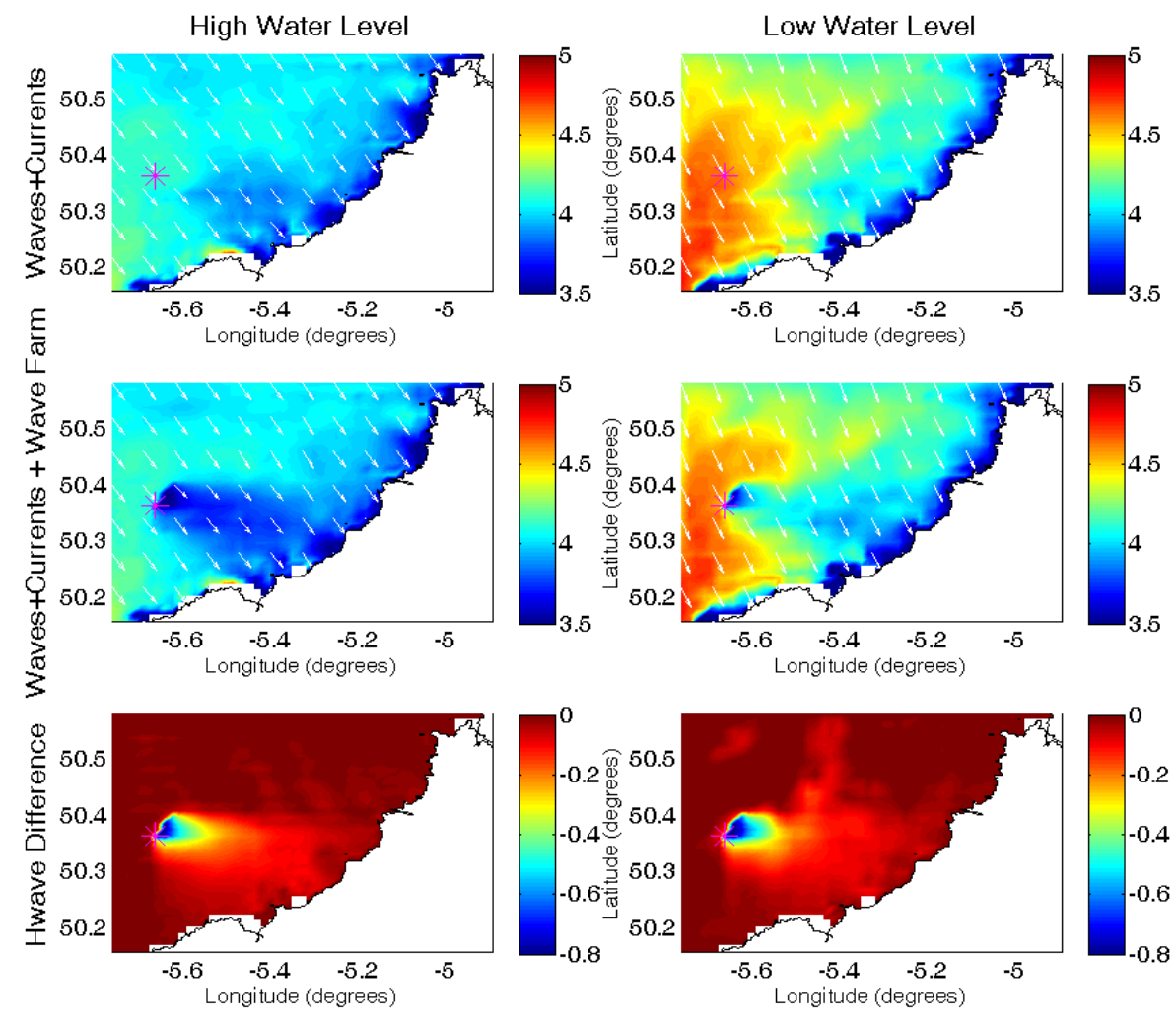

Figure 4. Effects of the wave farm on the wave heights under low and high water elevations: (top) computed wave height without wave farm; (middle) computed wave height with wave farm; (bottom) the difference of the computed wave height with and without wave farm. (Vectors are the wave directions; * - Wave Hub)

Figure 5 shows the bottom stress contribution for the coupled modelling system, with and without the wave farm, at the high and low water levels. The wave contribution on the bottom stress is large compared to tides only (not shown here), driving the sediment transport at the most, particularly during the storm peak. The bottom stress is also found to correlate with the currents field and is affected by the local water depth. As shown in Figure 4, the wave field, especially in the leeside of the wave farm, is affected significantly by the wave farm, it can be seen that the regions where significant bottom stress is affected are in the shallow water regions and the nearshore areas. The results also indicate the the water depth is an important factors to influence the bottom shear stresses. The maximum changes in bottom stress along the coast are found at the lower water elevation, and smaller bottom stress at the higher water elevation. Wave farm impact, on the bottom stress (right panels), is maximum at low water level, which is strongly correlated to the currents field, waves and depth.

\section{Effects of the wave farm on sediment transport}

After the model validation on hydrodynamics, the morphological modules were implemented to compute the sediment transport and the resulting bathymetry changes for cases with and without the presence of the wave farm. Due to the availability of wave buoys, the model was run for November 2010, when three storm events were observed at the Wave Hub site.

To study the effects of the wave farm on the sediment transport and morphological changes, we will focus on the analysis at the maximum storm peak, where further field measurements are available. Since this period differs from the previous period for model validation in Gonzalez-Santamaria et al, (2011), further model validations were carried out for this period. Water elevations were compared against tide gauges at four locations (not shown here) and wave heights were compared with the wave buoy data at three locations. The computed water elevations and the measurements from four tidal gauges around the study area show a good agreement, so do the computed wave heights and measurements by the wave buoys deployed at three locations close to the study site. In general the predicted wave heights closely follow the wind speed, and the storms are reproduced reasonably well. In comparison with the measurements, the storm peak was slightly under-predicted where water depths were relatively shallow. 

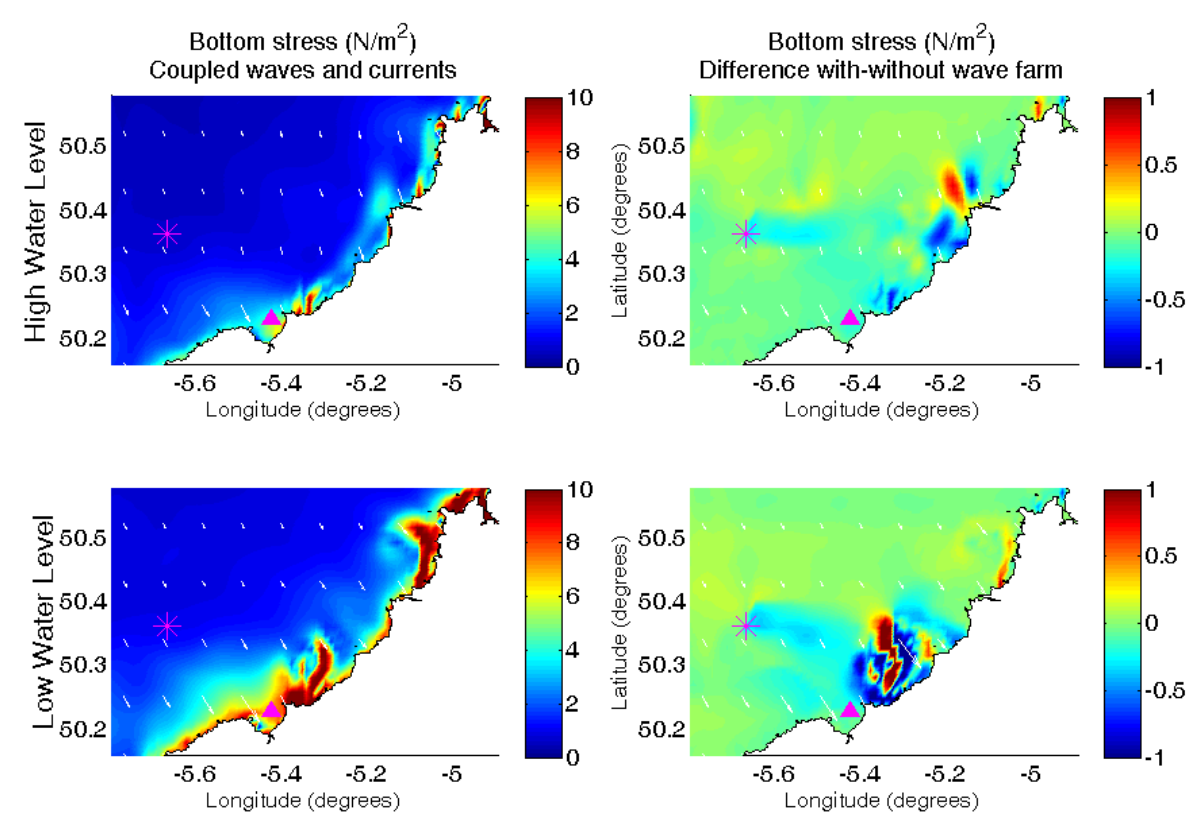

Figure 5. Effects of wave farm on bottom shear stresses at high and low tide. (Vectors are magnitude and direction of bottoms stresses, color indicates the magnitude, $\boldsymbol{\Delta}-\mathrm{St}$. Ives Bay, - Wave Hub)

In the coupled modelling system, bedload transport rates are calculated by the Soulsby and Damgaard (2005) formulae, which accounts for the combined effects of waves and currents on bedload flux. The suspended load is transported in the water column by solving the diffusion-advection equation, with additional a source/sink term added in exchange with the bed for vertical settling velocity and erosion. Erosion depends linearly on the bottom shear stress (Warner et al, 2008). Figure 6 shows the non-cohesive sediment (sand) concentration $\left(\mathrm{kg} / \mathrm{m}^{3}\right)$ for without wave farm (left panels) and the difference with and without the wave farm effect (right panels). We found strong sediment concentration at low tides along the coastline during the storm peak. As expected, the bottom stress distribution shown in Figure 5 has a strong correlation with the sediment concentration distribution in Figure 6. When the tidal currents are close to zero at high and low tide (top and bottom panels), the wave farm effect on the sediment distribution is mainly due to wave contribution. The maximum changes in sediment concentration with and without the wave farm are from -0.1 to $0.1 \mathrm{~kg} / \mathrm{m}^{3}$ during the tidal cycle and occur at the lee of the wave farm and near the coast north of St. Ives Bay. During the tidal cycle, the sediment concentration affected by the wave farm extends about $26 \mathrm{~km}$ northwards from St. Ives Bay at high tide. On the other hand, at the low tide, the sediment concentration moves slightly offshore, mainly in the lee of the wave farm, but with the maximum concentrations.

\section{Effects of the wave farm on morphological changes}

The changes of the sea bed are calculated from the convergence or divergence in sediment fluxes which are the sum of suspended and bedload transports (Warner et al, 2008). Due to the use of the coupled modelling system, the effect of morphological changes on flow and sediment transport is dynamically incorporated in the model.

Figure 7 shows the bed level changes over a 16-day duration of simulation, which includes three storm events. Figure 7(a) and (b) shows the bed level changes without and with wave farm, respectively. The general patterns of erosion and deposition are similar in both cases, where the most significant morphological changes are found in three bays along the coast, between $-1 \mathrm{~m}$ and $1 \mathrm{~m}$. The difference of the morphological changes with and without the wave farm is shown in Figure 7(c). The results show that the area near St. Ives Bay is most affected by the wave farm. This is expected as this area is located in the leeside of the wave farm and the predominant waves are north-easterly. The overall impact of the wave farm is found to cause more deposition in the south-west area and more erosion in the north-east area close to the St. Ives Bay where most bed changes are taking place. 

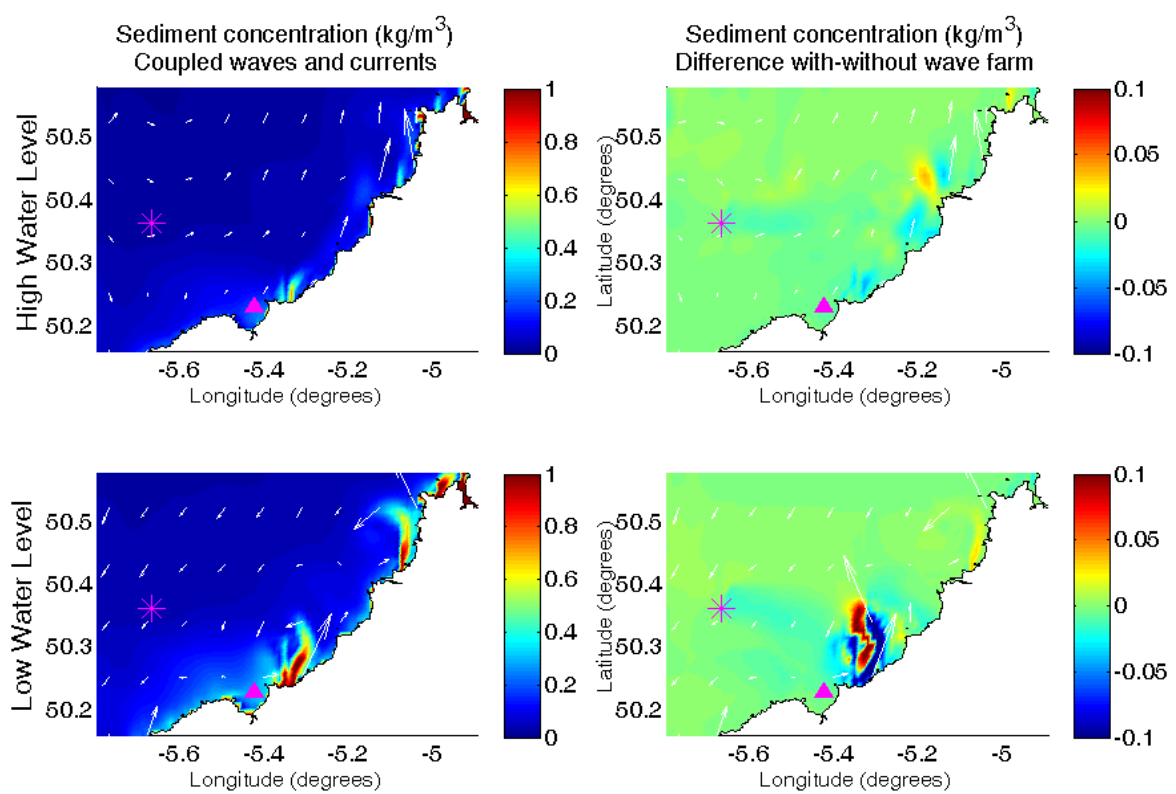

Figure 6. Effects of wave farm on sediment concentration under low and high water levels. (Vectors are magnitude and direction of current speed, color indicates the magnitude, $\Delta-$ St. Ives Bay, * - Wave Hub)
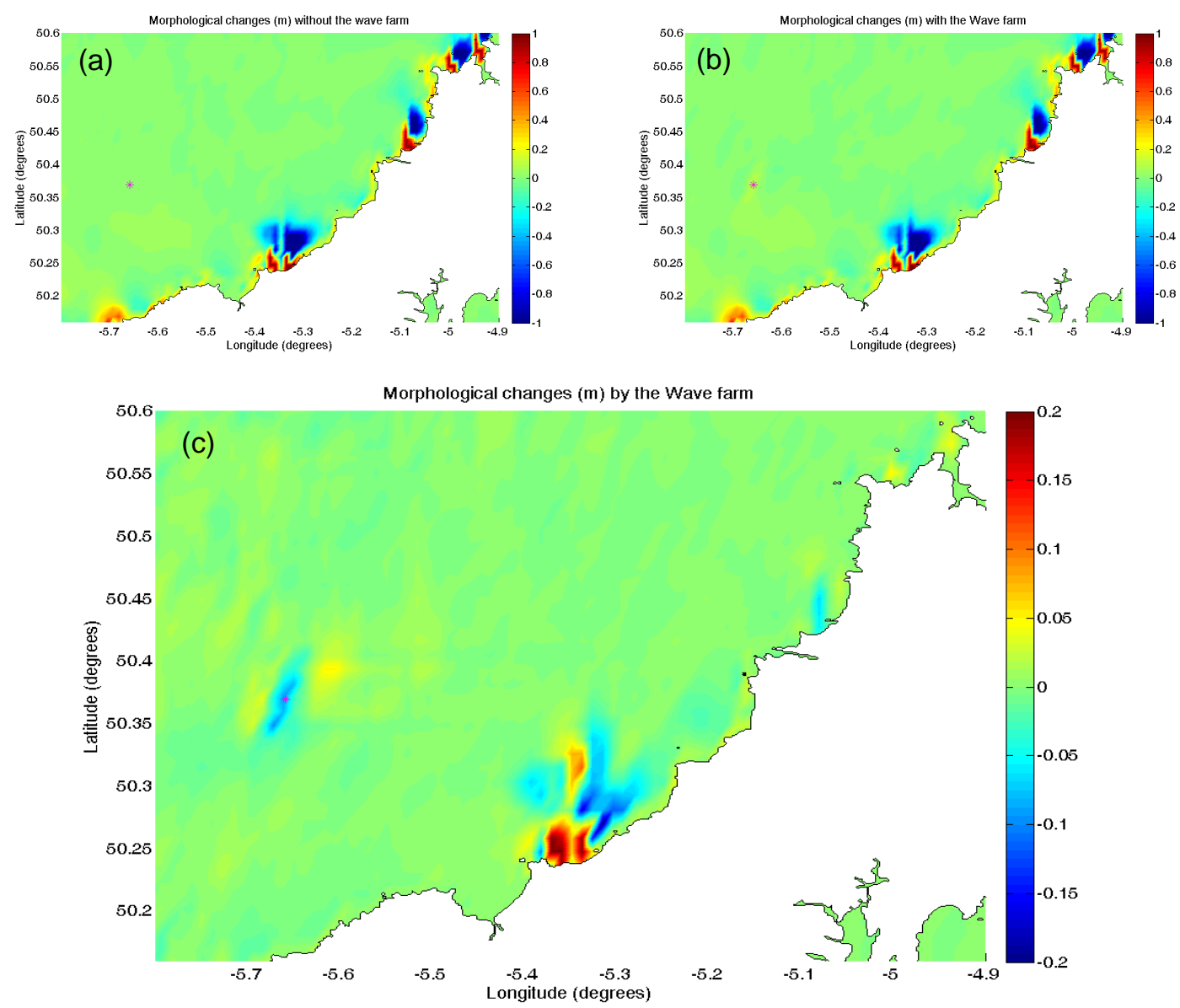

Figure 7. Effects of the wave farm on morphologic changes: (a) bed level changes without wave farm; (b) bed level changes with wave farm; and (c) difference of the bed level changes between (a) and (b). (*- Wave Hub) 


\section{CONCLUSIONS \& DISCUSSIONS}

A two-way coupled modelling system with SWAN and ROMS models implemented with sediment transport modules has been used to study the impact of a wave farm at the Wave Hub site in the South West of England on nearshore morphodynamics. The modelling system was calibrated against various field measurements, showing a good agreement.

It was found that the sediment concentration is higher at the lee of the wave farm, presumably because the longshore current is partially blocked by the circulation currents (in the lee), producing some of the longshore currents to be diverted outside the wave farm. The littoral transport in the lee of the wave farm decreases due to the attenuated wave and longshore currents in the area sheltered by the wave farm. This causes the trapping of sand in the lee, depending on the hydrodynamic conditions, as the wave farm reflects and dissipates some of the incoming wave energy, thus, it reduces wave heights and shore erosion in the shadowed area of the wave farm. Moreover, the littoral transport of sediments is deposited in the lower wave energy region. The diversion of the longshore currents will cause the development of local erosion close to the heads of the obstacle or wave farm. An obstacle, in this case the wave farm, traps sand under all circumstances, hence, there will be a coastal impact in any circumstance.

The maximum changes in sediment concentration with and without the wave farm are from - 0.1 to $0.1 \mathrm{~kg} / \mathrm{m}^{3}$ at low tide and occur at the lee of the wave farm, the changes are much more profound in the nearshore area north of St Ives Bay. From low tide to high tide, the sediment concentration extends about $26 \mathrm{~km}$ upwards from St. Ives Bay along the coast. At the low tide, the sediment concentration moves in slightly offshore. These results are closely correlated to the bottom stress results. The bedload rate flux is considerable reduced when the wave farm is positioned in the study area, also it is shown that at the peak of the three storm events, the bedload rate flux is decreased.

The significant impacts of the wave farm on the morphological changes are again found in the coastal area near St. Ives Bay, as well as in immediate lee side of the wave farm. The bed changes indicate a northward shift of erosion and deposition pattern due to the wave diffraction caused by the wave farm.

\section{ACKNOWLEDGMENTS}

The first author would like to thank the National Council of Science and Technology of Mexico (CONACYT-MEXICO) for the funding and support of this research. The authors also acknowledge the support from the Southwest Regional Development Agency, UK. The second author would like to acknowledge the support of the start-up fund provided by the University of Maine.

\section{REFERENCES}

Booij N., Ris R.C., Holthuijsen L.H. 1999. A third generation wave model for coastal regions, part I, model description and validation, Journal of Geophysical Research 104 (C4), 7649-7666.

Bowen A. J., 1969.The generation of longshore currents on a plane beach, Journal of Marine Research, 27, 206-214.

Buscombe D.D., Scott T.M. 2008. The coastal geomorphology of north Cornwall, Wave Hub impact on seabed and shoreline processes - report [online]. Available: http://www.research.plymouth.ac.uk-/whissp/index.html/

Egbert G. D., Erofeeva S. Y. 2002. Efficient inverse modeling of barotropic ocean tides, Journal of Atmospheric and Oceanic Technology, 19, 183-204.

Gonzalez-Santamaria R., Zou Q.-P. and Pan S. 2011. Two-way coupled wave and tide modelling of a wave farm, Journal of Coastal Research, SI 64, 1038-1042, ISSN 0749-0208.

Gonzalez-Santamaria R., Zou Q.-P. and Pan S. 2012. Impacts of a wave farm on waves, currents and coastal morphology, Journal of Estuaries and Coasts, SI: Renewable Ocean Energy. (under review).

Grant W.D., Madsen O.S. 1979. Combined wave and current interaction with a rough bottom, Journal of Geophysical Research, 84 (C4), 1797-1808.

Longuet-Higgins M. S., Stewart R. W. 1962. Radiation stress and mass transport in gravity waves, with application to 'surf beats', Journal of Fluid Mechanics 13 (4):481-504.

Millar D.L., Smith H.C.M., Reeve D.E. 2007. Modelling analysis of the sensitive of shoreline change to a wave farm, Ocean Engineering, 34, 884-901. 
Mulligan R. P., Hay A. E., and Bowen A. J. 2008. Wave-driven circulation in a coastal bay during the landfall of a hurricane, Journal of Geophysical Research, 113, C05026, doi:10.1029/2007JC004500.

NOAA Wavewatch III. NOAA/NCEP Operational wave models. [online]. Available: http://polar.ncep.noaa.gov/waves.

Padman L. and Erofeeva S. 2004. A barotropic inverse tidal model for the Arctic Ocean, Geophysical Research Letters, vol. 31.

Soulsby R.L., Damgaard J.S. 2005. Bedload sediment transport in coastal waters, Journal of Coastal Engineering, 52 (8), 673-689.

SWRDA - South West of England Development Agency, Wave Hub development and design phase, SWRDA Group Limited, coastal processes study report. [online]. Available: http://www.wavehub.co.uk/

Warner J.C., Sherwood C.R., Signell R.P., Harris C.K., Arango H.G. 2008. Development of a three dimensional, regional, coupled wave, current, and sediment transport model, Journal of Computers \& Geosciences, 34, 1284-1306.

Zou Q.P. 2004. A simple model for random wave bottom friction and dissipation, Journal of Physical Oceanography, 34 (6), 1459-1467.

Zou, Q.-P., Bowen A. J. \& Hay A. E. 2006. The vertical distribution of wave shear stress in variable water depth: theory and field observations. Journal of Geophysical Research, 111 (C09032), doi:10.1029/2005JC003300. 